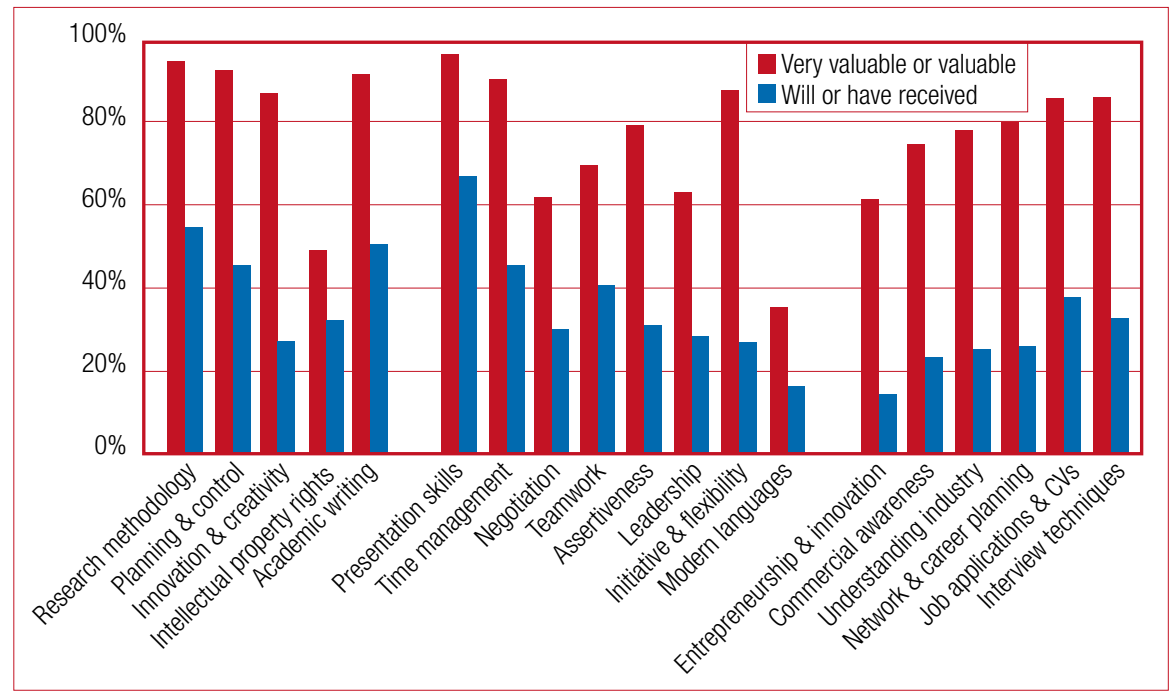

The value attached to different types of training by $\mathrm{PhD}$ students and their expectation of receiving that training at their university. (Source: EPSRC.)

given the supply and demand of academic jobs. "Training in methods of research should produce individuals capable of a variety of jobs. If a PhD fails in that, then it is wrong," says David Southwood, former head of the physics and astronomy department of Imperial College, London.

\section{Protecting intellectual property}

"Students need an awareness of the significance of patenting and protecting intellectual property," says Andy Brass, a reader in the school of biological sciences at the University of Manchester. Brass masterminded Manchester's MSc in bioinformatics and has himself turned entrepreneur, founding the company Bioinformatics Solutions (see Box on p. A8). Brass argues that students need to know how to keep lab notebooks to support a claim. In the United States, patents are awarded to the first to invent, so each page of a lab notebook needs to be countersigned every day. "You do this in an industrial lab, so you may as well learn the discipline during a PhD," says Brass. "It's

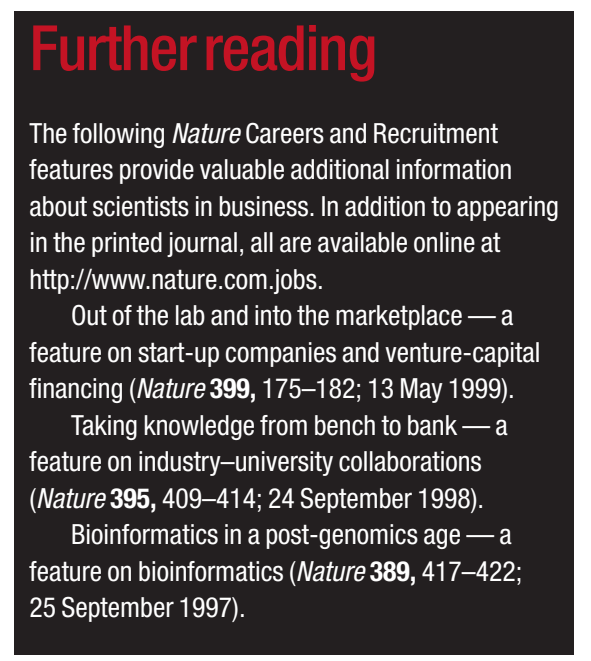

worth doing because if an idea is not protected by a patent, no one is going to invest in developing a product."

If skills training is offered on a patchy basis for $\mathrm{PhD}$ students, the situation is even more acute for postdocs. Yet this group faces serious dilemmas of short-term contracts, low pay and lack of career prospects in academic institutions.

Recognizing the unfairness of this position, the research councils, Royal Society, British Academy and the committee of vice chancellors and vice principals agreed in September 1995 to work for improved pay,

\begin{abstract}
here is, say physicists in industry, a mismatch between the skills needed in the private sector, including research, and those acquired while employed as a postdoc. Furthermore, although higher education institutions remain the main employers of physics postdocs, only a quarter of those surveyed could cite good examples of training and development in their universities.
\end{abstract}

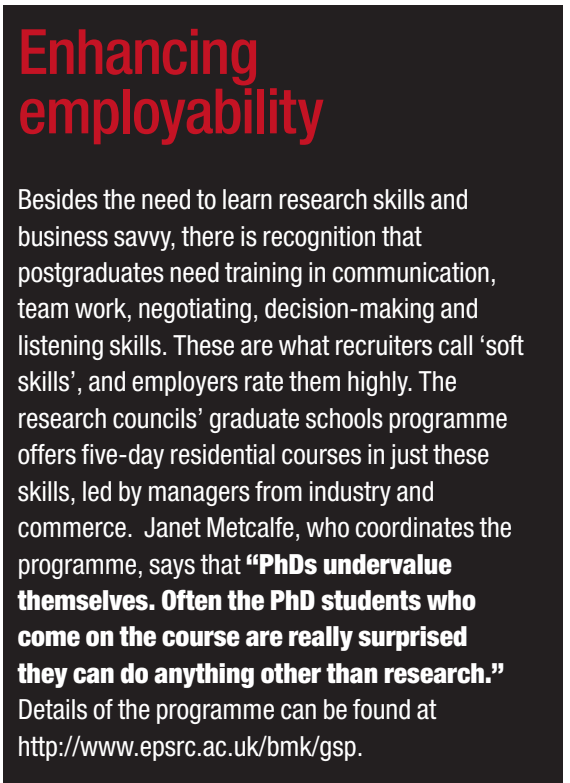

conditions and training for postdocs. "We are making some progress, but it's patchy," says Bob Price, head of human resources and development at the Biotechnology and Biological Sciences Research Council. Price attributes this to postdocs wanting to do academic research and not necessarily seeing the value of transferable skills, and to universities wanting to keep costs down. Given these circumstances, Brass argues that after one postdoc you should think seriously about what to do next: "If after one postdoc your position is not strong enough to get a fellowship, then re-evaluate."

\title{
Where do all the postdocs go?
}

\section{A survey of contract research staff by the Institute of Physics presents employment statistics of physics postdocs and has uncovered disturbing news about the need for wider skills training of postdocs in universities.}

The finding emerged in a study commissioned by the Institute of Physics (IoP) to find out what physicists do for a living and what are their aspirations and experiences. Published this summer, the survey results were based on responses from 448 people who started their first postdoc between 1988 and 1993. The survey team also questioned a group of 236 people who began their $\mathrm{PhD}$ between 1994 and 1995. All had experience 


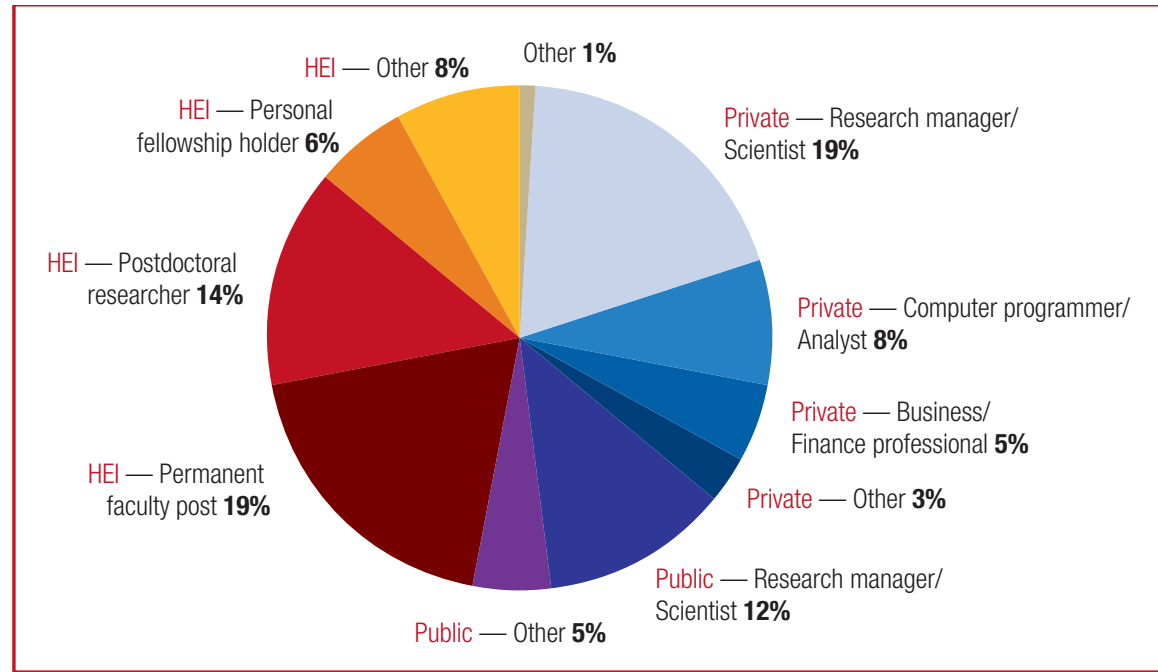

Employment destinations of physics postdocs. (Source: IoP.)

of one or two contract research posts.

Just over a third of postdocs have jobs in the private sector. The public sector employs 17 per cent of physicists and a mere 2 per cent have jobs teaching in schools and colleges. Higher education institutions employ the remaining and largest group of physicists. High-tech, leading-edge manufacturers, business/financial firms and software/computing companies are the main private sector employers.

To succeed in these jobs, physicists listed the five most important skills they needed. These were, in descending order, project planning and management; presentation and communication skills; leadership skills; problem-solving skills; and individual initiative and self-motivation. By contrast, the five principal lessons they had learned as contract researchers were subject-specific knowledge; presentation and communication skills; technical research skills; individual initiative and self-motivation; and problem-solving skills. This mismatch is important given that only one in five postdocs will become permanent faculty members. More information about getting a permanent faculty post was one of the issues that postdocs considered
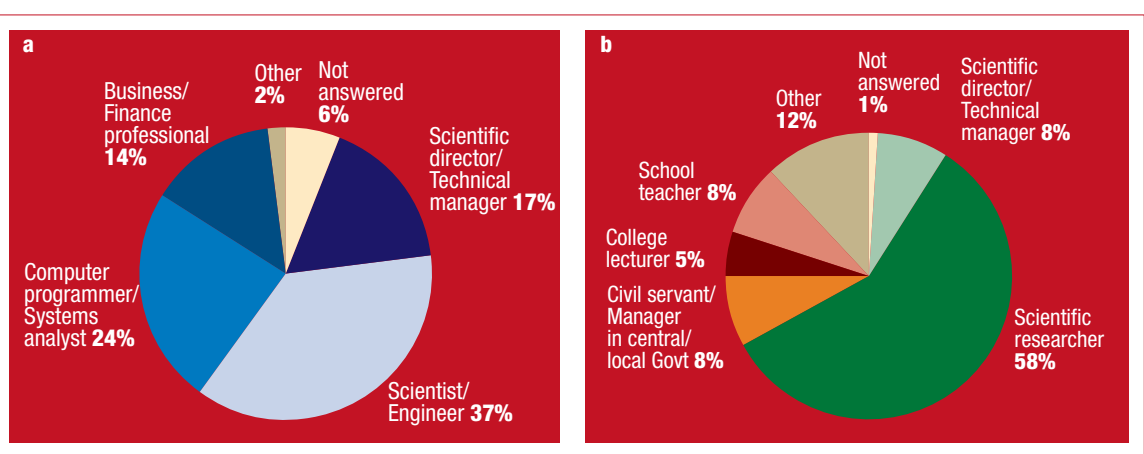

Occupations of physics postdocs: $a$, in the private sector; $b$, in the government, public and voluntary sector. (Source: IoP.) important. They also said that the research councils should allocate money for training and development.

Of those currently employed by the private sector, only 50 per cent would do a postdoc again. In the public sector and higher education, however, nearly all physicists would, if they had the decisions to make again, pursue postdoc experience. When questioned about whether they would consider teaching in schools as a profession, three quarters of postdocs were adamant that they would not, although the 1994-95 cohort was less resistant to the idea of a career in teaching.

Despite the uncertainty of a postdoc's life, the intellectual satisfaction of academic research remains a powerful pull. Nearly half the postdocs are still employed by higher education institutions. Of those, about 40 per cent have permanent faculty posts. The rest are postdocs (30 per cent), fellows (13 per cent) or have other posts (17 per cent). Half of those who are still postdocs stay in the universities because they enjoy the research. This is despite knowing they are unlikely to get a permanent faculty position and that they would be financially

\begin{tabular}{l} 
Annual gross salaries of physics postdocs \\
\hline Gross salary
\end{tabular}

better off in industry and could be undertaking challenging research there. The other half of postdocs still harbour hopes of a permanent post.

The survey Career Paths of Physics Post-Doctoral Research Staff is published by the Institute of Physics (email: physics@iop.org).

\section{Job search}

The career paths survey by the Institute of Physics (IoP) gives a good idea of the spread of business sectors in which physicists are employed. Company websites are, obviously, an important source of information about the type of people sought by these industries.

The websites of both the loP (http://www.iop.org) and the American Institute of Physics (AIP; http://www.aip.org/careers) are professional and full of content. The AIP's site is well worth a look even if you are not job hunting in the United States. Networking, says the AIP, is very important, both at conferences and through the Internet. The loP produces a range of booklets and multimedia packages with practical information. Titles include Scientists in Business, Starting as a Consultant and Building Careers that Fit. Although aimed at physicists, they contain some general advice that could help people from any discipline.

If you are interested in teaching, the government announced a $£ 5,000$ incentive in 1998. The first $£ 2,500$ is paid during teacher training and the second instalment is paid at the start of teaching. More information can be found at http://www.go4itnow.com and http://www.teachtta.org.uk.

For further reading, see the Nature Careers and Recruitment feature 'Physics grapples with its image problem', available online at http://www.nature.com/jobs or in Nature 398, 265-268 (18 March 1999). 